\title{
Numerical simulation of heat transfer improvement in the divertor of fusion reactors by using $\mathrm{Al}_{2} \mathrm{O}_{3}$ nanofluid
}

\author{
Hadighe Ashouri $^{1} \cdot$ Abbas Ghasemizad $^{1} \cdot$ Seyyed Mahmoud Sadatkiae ${ }^{2} \cdot$ Asghar Seddighzade $^{2}$
}

Received: 18 June 2018 / Accepted: 16 December 2018 / Published online: 27 December 2018

(c) The Author(s) 2018

\begin{abstract}
The objective of this work is to study the effect of using nanofluids as coolant on divertor system of fusion reactors which is known to be subjected to high heat loads coming from the plasma. Turbulent force convective heat transfer of water-based $\mathrm{Al}_{2} \mathrm{O}_{3}$ nanofluid flowing through the $\mathrm{CuCrZr}$ cooling tube of a small scale of mock up made of five tungsten monoblocks has been numerically investigated using single phase model. Computational fluid dynamic approach has been applied by using CFD software FLUENT 6.3.26. The computed results have been validated by traditional corrections expression reported by previous works. The dependence of temperature contours and profiles on volume fraction of nanofluids for different walls of this monoblock has been studied and compared with pure water. The maximum allowed temperature of the candidate material under unusual situation of a fusion reactor has been considered and compared with the maximum temperatures resulted from the CFD results. The effects of various nanofluid concentrations and Reynolds numbers on average Nusselt number have been also investigated. The results show a significant improvement in heat removal from the divertor under the cooling of alumina/water nanofluid with respect to pure water.
\end{abstract}

Keywords Fusion reactor · Divertor · Nanofluid $\cdot$ Heat transfer $\cdot$ Single phase $\cdot$ CFD

\section{List of symbols}

$c_{\mathrm{p}} \quad$ Specific heat capacity at constant pressure $(\mathrm{J} / \mathrm{kg} \mathrm{K})$

$k \quad$ Thermal conductivity $(\mathrm{W} / \mathrm{m} \mathrm{K})$

$q \quad$ Heat flux, $\mathrm{W} / \mathrm{m}^{2}$

$h \quad$ Heat transfer coefficient $\left(\mathrm{W} / \mathrm{m}^{2} \mathrm{~K}\right)$

$\mathrm{Nu} \quad$ Nusselt number

$T \quad$ Temperature (K)

Re Reynolds number $\left(\frac{\rho D V}{\mu}\right)$

$P \quad$ Pressure $(\mathrm{Pa})$

$V \quad$ Velocity $(\mathrm{m} / \mathrm{s})$

$T \quad$ Temperature (K)

$D \quad$ Tube diameter $(\mathrm{m})$

Pr Prandtl number $\left(\frac{c_{p} \mu}{k}\right)$

$w \quad$ Wall

$L \quad$ Length of the tube (m)

Abbas Ghasemizad

aghsemizad@gmail.com; ghasemi@guilan.ac.ir

1 Physics Department, University of Guilan, P.O. Box 41335-1914, Rasht, Iran

2 Nuclear Science and Technology Research Institute (NSTRI), Nuclear Science Research School, A.E.O.I, P.O. Box 14155-1339, Tehran, Iran

\author{
Greek letters \\ P Density $\left(\mathrm{kg} / \mathrm{m}^{3}\right)$ \\ $\varepsilon \quad$ Rate of dissipation per unit mass $\left(\mathrm{m}^{2} / \mathrm{s}^{3}\right)$ \\ $\kappa \quad$ Turbulence kinetic energy $(\mathrm{J})$ \\ $\mu \quad$ Dynamic viscosity (Pa.s) \\ $\phi \quad$ Volume fraction (vol.\%) \\ Subscripts \\ np Nanoparticles \\ nf Nanofluid \\ f Fluid \\ w Wall
}

\section{Introduction}

Divertor (Fig. 1a) [1] is possibly the most critical component in the future fusion reactors. As it is subjected to high heat loads, up to $10 \mathrm{MW} / \mathrm{M}^{2}$ in ITER and even more in DEMO, it may act as an exhaust for the first wall, capable of transferring the heat concentration out of the first wall. Plasma-facing components (PFC) named the dome and targets, as shown in Fig. 1a, are the main parts of divertor, which should sustain these extreme heat fluxes. Here, heat transfer in target part is under discussion, so another view 


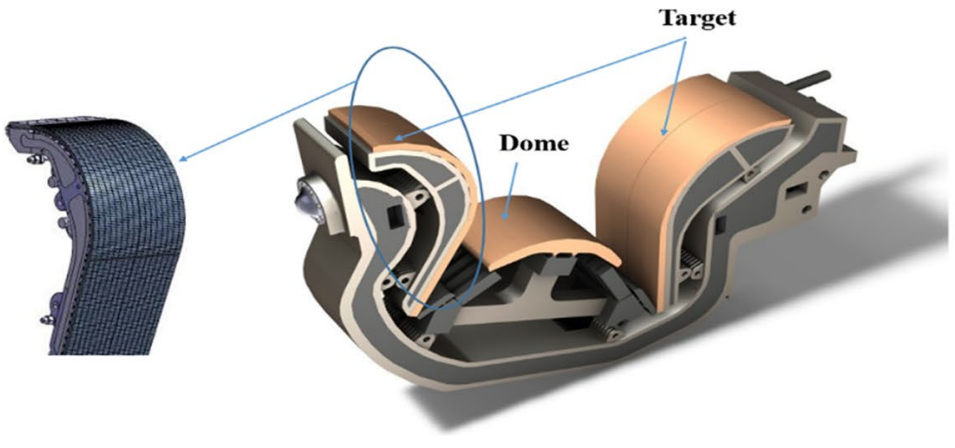

(a)

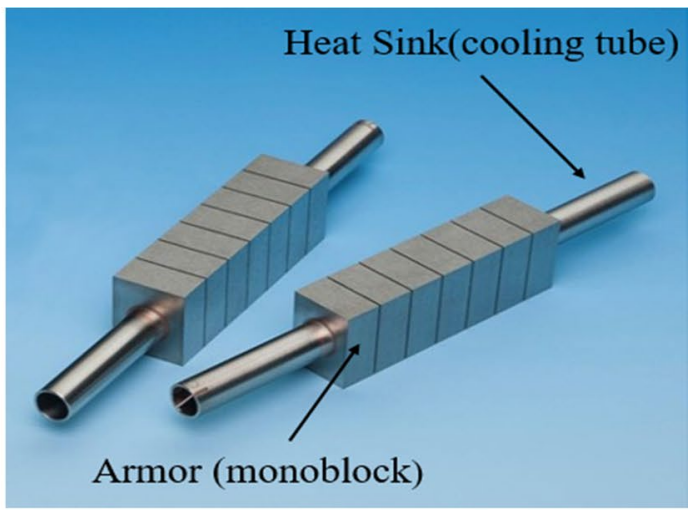

(b)

Fig. 1 Divertor and the different parts of it: a dome and target parts; $\mathbf{b}$ small scale of mock-up made of seven tungsten monoblocks and the cooling tube

of the target is shown in Fig. 1a. Targets are made of some monoblocks (Fig. 1b) [2] (in this figure seven monoblocks can be seen) with two parts, and every part is made of special material: armor materials (monoblocks), the part which is in direct contact with plasma, and structural materials (cooling tube) which acts as the heat sink [3-5].

Tungsten (W) has always been a promising material considered for armor material. High melting point and high thermal conductivity besides low erosion rate and low tritium retention under plasma condition are among the key advantages of tungsten. Because of the high thermal conductivity, copper or its alloys like CuCrZr (copper-chromium-zirconium) are likely the best candidate material for heat sink. Due to the difference between thermal expansion coefficient of $\mathrm{W}$ and $\mathrm{CuCrZr}$, it is possible to have thermal stress concentration on the $\mathrm{W} / \mathrm{CuCrZr}$ interface leading to failures, e.g., cracks on the boundary between them [4]. To solve this problem, an interlayer between the $\mathrm{CuCrZr}$ coolant pipe and the $\mathrm{W}$ monoblock is proposed with the aim of reducing the thermal mismatch stress between the armor and the structure. In this work, the pure copper (CuOFHC) is proposed [6-8]. Figure 2 shows a fluid-cooled monoblock designed based on the above explanation.

On the other hand, the heat management requirements give a great importance to coolant specification in divertor area of a fusion reactor. Water has always been a promising coolant, and there are lots of literature focusing on water and its characteristic [6, 8-10], but there are some disadvantages for water such as high pumping power and limited power handling caused by critical heat flux (CHF) [11].

Fortunately, these problems can be removed by the use of nanofluids. Using nanofluids leads to a great enhancement in CHF [12] and decreases the pumping power requirement. A nanofluid is a suspension of low concentration (below $10 \%$ vol.) of nanoparticles like aluminums oxide $\left(\mathrm{Al}_{2} \mathrm{O}_{3}\right)$, titanium oxide $\left(\mathrm{TiO}_{2}\right)$ and copper oxide $(\mathrm{CuO})$ and a base fluid (such as water or ethylene glycol) [13]. Using nanofluid to improve thermal properties of cooling fluid is dated back to 1990 s by Choi $[14,15]$. He reported a noticeable improvement in thermal properties and coined the nanofluid
Fig. 2 One of the monoblocks designed here

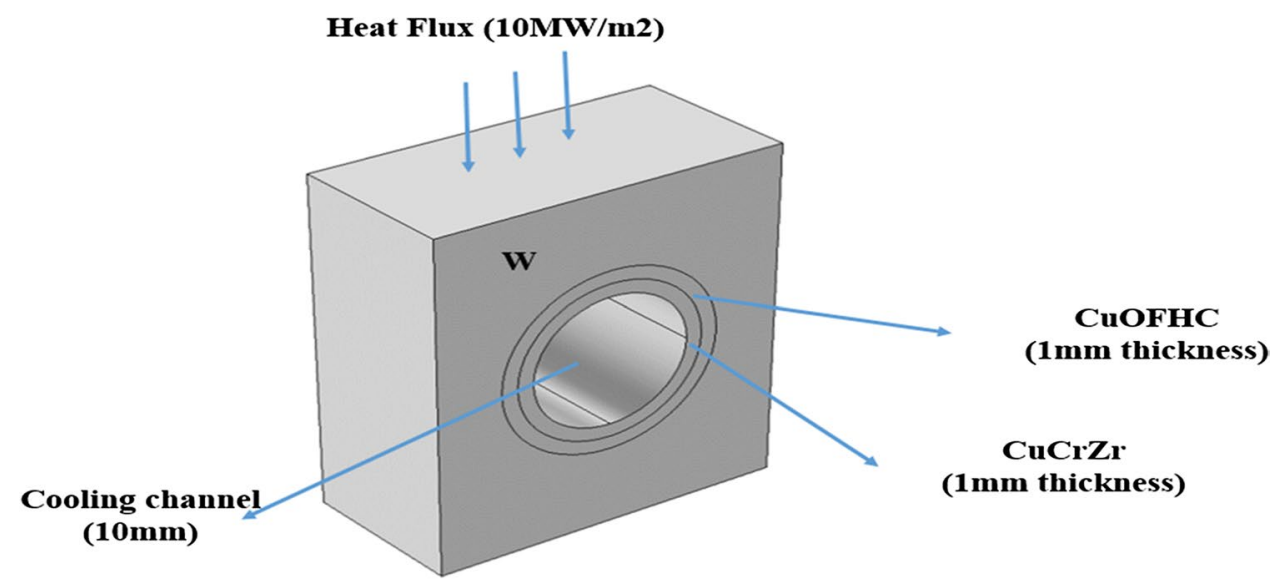


term. Since then, many researches have showed the favorable results of adding nanoparticles to base fluids both numerically and experimentally [16]. The proven advantage of using nanofluid is better heat characteristics like higher heat transfer coefficients even in low volume fractions of nanoparticles. Regarding these suitable properties of nanofluid, using nanofluid in high heat flux systems such as solar collectors, electronic cooling systems and nuclear reactors to reduce temperature and making a more uniform temperature distribution seem attractive.

Some researchers have used nanofluid in nuclear systems for study. Wu and Zhao [13] in reviewing nanofluid heat transfer and critical heat flux enhancement especially in nuclear reactor have claimed that to turn nanofluid application from vision to reality, we need to first overcome some challenges, like a precise database of nanofluid thermophysical properties and nanofluid stability in real working condition. Zarifi et al. performed a neutronic simulation of different nanofluids in VVER-1000 reactor [13]. Their research aimed at optimization of type and characteristics. They also studied thermal-hydraulic modeling of nanofluid in this reactor, showing remarkable differences between nanofluid and pure water by increasing the concentration of nanoparticles [17]. Few researches have been done on using nanofluids in fusion-based systems. Barret et al. [11] experimentally investigated using nanofluid in fusion-relevant geometries with focus on studying nanofluid behavior in such environment. They showed an initial assessment of suitability of nanofluids as coolant in a fusion reactor.

In this study, a numerical investigation of the turbulent forced convection flow of aluminum oxide $\left(\mathrm{Al}_{2} \mathrm{O}_{3}\right)$ nanofluid in the cooling tube of a monoblock of a divertor has been under consideration. The CFD analysis has been done by FLUENT software based on finite volume method.

\section{Mathematical formulation and numerical procedure}

\section{Geometry and material}

The geometry of the divertor $\mathrm{W}$ monoblock considered here is shown in Fig. 2. It is a $22 \times 26 \times 11 \mathrm{~mm}$ rectangular tungsten which is subjected to a heat flux load of $10 \mathrm{MW} /$ $\mathrm{m}^{2}$ from the top surface in contact with plasma. Cooling tube is made of $\mathrm{CuCrZr}$ with the diameter of $10 \mathrm{~mm}$. The inlet coolant has the pressure of $4.2 \mathrm{MPa}$ and the temperature of $120^{\circ} \mathrm{C}$, and the velocity between 8 and $15 \mathrm{~m} / \mathrm{s}$ associated with different mass flow rates (Reynolds num-

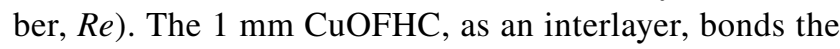
cooling tube to $\mathrm{W}$ monoblock.

To have a more real condition like what has been considered in experimental studies, five monoblocks like the one described above with a $0.5-\mathrm{mm}$-thin gap between them and a $100 \mathrm{~mm}$ cooling tube have been used. The geometry and componential mesh (Fig. 3) was generated in GAMBIT, a preprocessing module for the FLUENT. First, edges, surfaces and volumes have been produced, respectively, and then by applying some logic operations (like partitions, an individual entity into two separate virtual (subset) entities) and meshing by block cells, the final geometry has been constructed.

A grid independence procedure was implemented over grids with different cell numbers for optimizing the mesh size. To obtain grid independence solution, the cell numbers were adjusted around 289,012 to 601,033 cells. Four sets of grid systems were used in a calculation for a grid independence test at different Reynolds numbers for nanofluid with volume fraction of $2 \%$, to confirm the accuracy

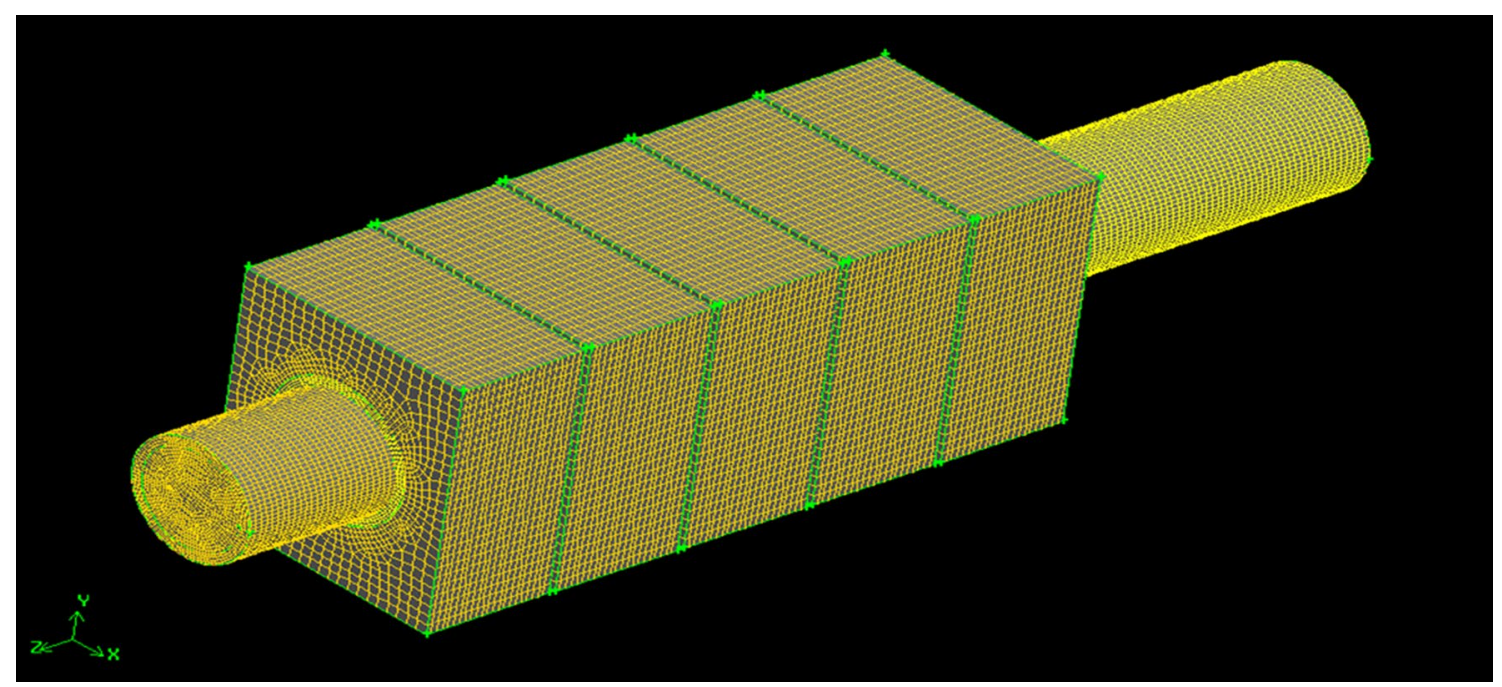

Fig. 3 Final geometry created in GAMBIT and imported in FLUENT 


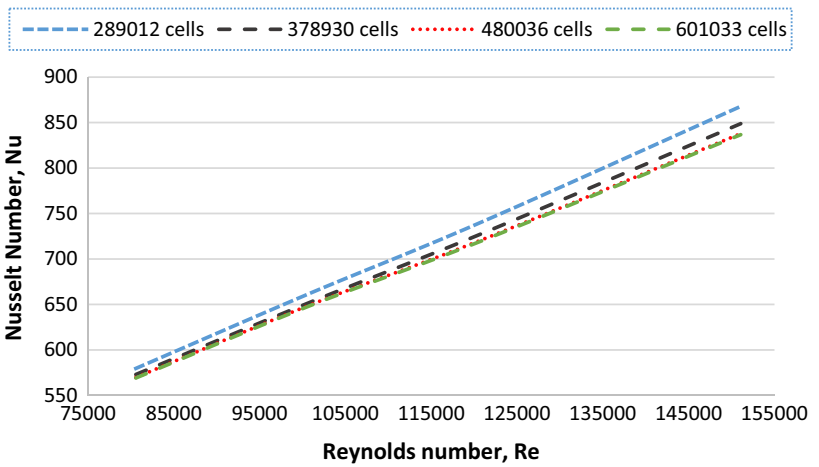

Fig. 4 Grid independence test

Table 1 Thermo-physical properties of nanoparticles and base fluid $[18,19]$

\begin{tabular}{lllcl}
\hline $\begin{array}{l}\text { Property } \mu \\
(\mathrm{kg} / \mathrm{m} \mathrm{s})\end{array}$ & $C(\mathrm{~J} / \mathrm{kg} \mathrm{K})$ & $\rho\left(\mathrm{kg} / \mathrm{m}^{3}\right)$ & $k(\mathrm{~W} / \mathrm{m} \mathrm{k})$ & \\
\hline Water & 4182 & 998 & 0.6 & 0.001003 \\
$\mathrm{Al}_{2} \mathrm{O}_{3}$ & 880 & 3900 & 42.3 & \\
\hline
\end{tabular}

of the numerical solutions. Grid independence solution is evaluated by comparing the heat transfer results of different grid levels as shown in Fig. 4. Therefore, grid system with 480,036 elements was adopted in the subsequent simulations due to a good compromise of computational time and solution precision. For the near wall region, the thermal and velocity layers have high effect on the heat transfer coefficient and Nusselt number. Thus, the mesh with high density is applied in this region. A hexahedral mesh with grid adoption for $y+=1.92$ at adjacent wall region is used to resolve the sub-layer with a refined mesh density in the regions near the wall boundaries.

\section{Physical properties of nanofluid}

Table 1 shows the properties of water as the base fluid and the $\mathrm{Al}_{2} \mathrm{O}_{3}$ nanoparticles. To calculate physical properties of $\mathrm{Al}_{2} \mathrm{O}_{3}$ /water nanofluid with volume fraction $(\varphi)$ of $1-4 \%$, we use formulas which are available in the literature as follows:

With regard to the concept of Mixing theory, the density of a nanofluid $\left(\rho_{\mathrm{nf}}\right)$ be calculated as [20]

$\rho_{\mathrm{nf}}=(1-\varphi) \rho_{\mathrm{f}}+\varphi \rho_{\mathrm{np}}$

where $\rho$ is density and the subscripts $\mathrm{f}, \mathrm{nf}$ and np are related to fluid, nanofluid and nanoparticles, respectively.

And according to the thermal equilibrium model, the specific heat capacity of the nanofluid $\left(c_{\text {p.nf }}\right)$ can be written as $c_{\mathrm{p} . \mathrm{nf}}=\frac{(1-\varphi)\left(\rho c_{\mathrm{p}}\right)_{\mathrm{f}}+\varphi\left(\rho c_{\mathrm{p}}\right)_{\mathrm{np}}}{\rho_{\mathrm{nf}}}$

There are lots of studies considering the thermal conductivity of nanofluids [21-23]. According to some literature [15, 24], thermal conductivity of alumina nanofluids $\left(k_{\mathrm{nf}}\right)$ are in good agreement with Maxwell model. Then, Maxwell equation has been used here as follows [25]

$k_{\mathrm{nf}}=k_{\mathrm{f}} \frac{k_{\mathrm{np}}+2 k_{\mathrm{f}}+2 \varphi\left(k_{\mathrm{np}}-k_{\mathrm{f}}\right)}{k_{\mathrm{np}}+2 \varphi\left(k_{\mathrm{np}}-k_{\mathrm{f}}\right)}$

For viscosity, Brinkman model which is a good prediction of viscosity for alumina nanofluids $\left(\mu_{\mathrm{nf}}\right)$ in low concentration of nanoparticles has been taken [26]

$\mu_{\mathrm{nf}}=\frac{\mu_{\mathrm{f}}}{(1-\varphi)^{2.5}}$

Local convective heat transfer coefficient $(h(z))$ and Nusselt number $(\mathrm{Nu})$ are defined as follows [27]

$h(z)=\frac{q}{T_{\mathrm{w}}(z)-T_{\mathrm{f}}(z)}$

$N u(z)=\frac{h(z) D}{\mu}$

where $q, D$ and $T_{\mathrm{w}}$ are heat flux, tube diameter and wall temperature, respectively.

\section{Governing equations}

Single-phase approach has been chosen here to numerically simulate forced convective heat transfer behavior of alumina nanofluids inside a heated tube under steady heat flux coming from a divertor of fusion reactor. Equations (1), (2), (3) and (4) are used to define the nanofluid properties in UDF codes imported in FLUENT software.

The popular singe-phase model assumes that nanoparticles have been uniformly distributed in the base fluid and these two parts of nanofluids are in thermal equilibrium and move with the same velocity. Also, as it can be seen from the relations of physical properties of nanofluids, they are based on the mixture of nanoparticles and base fluids [28-30]

The general forms of governing equation for steady-state flow and heat transfer of nanofluids are as follows

Conservation of mass:

$\nabla \cdot\left(\rho_{\mathrm{nf}} \boldsymbol{V}\right)=0$

where $\boldsymbol{V}$ is velocity 
Conservation of momentum:

$\nabla \cdot\left(\rho_{\mathrm{nf}} \boldsymbol{V} \boldsymbol{V}\right)=-\nabla P+\mu_{\mathrm{nf}} \nabla^{2} \boldsymbol{V}$

where $P$ is pressure.

Conservation of energy:

$\nabla \cdot\left(\left(\rho c_{\mathrm{p}}\right)_{\mathrm{nf}} \boldsymbol{V T}\right)=\nabla \cdot\left(k_{\mathrm{nf}} \nabla T\right)$

To simulate turbulence, we use standard $\kappa-\varepsilon$ (k-epsilon) turbulent model because of its reasonable accuracy and fast convergence [31, 32]. This model introduces two external equations for turbulence kinetic energy $(\kappa)$ and rate of dissipation $(\varepsilon)$ as follows [33]

$\rho(\boldsymbol{V} \cdot \nabla) \kappa=\nabla \cdot\left(\left(\mu+\frac{\mu_{T}}{\sigma_{\kappa}}\right) \nabla \kappa\right)+G_{\kappa}-\rho \varepsilon$

$\rho(\boldsymbol{V} \cdot \nabla) \varepsilon=\nabla \cdot\left(\left(\mu+\frac{\mu_{T}}{\sigma_{\varepsilon}}\right) \nabla \varepsilon\right)+C_{\varepsilon 1} \frac{\varepsilon}{\kappa} G_{\kappa}-C_{\varepsilon 2} \rho \frac{\varepsilon^{2}}{\kappa}$

In these equations, $\mathrm{G}_{\kappa}$ represents the generation of turbulence kinetic energy due to the mean velocity gradients:

$G_{\kappa}=\mu_{T}\left(\nabla \boldsymbol{V}+(\nabla \boldsymbol{V})^{T}\right)$

$C_{\varepsilon 1}$ and $C_{\varepsilon 2}$ are constants. $\sigma_{\kappa}$ and $\sigma_{\varepsilon}$ are the turbulent Prandtl numbers for turbulent kinetic energy and the rate of dissipation, respectively, and $\mu_{T}$ is the eddy viscosity which couples $\kappa$ and $\varepsilon$ to governing equations and is modeled as

$\mu_{T}=\rho C_{\mu} \frac{\kappa^{2}}{\varepsilon}$

Other constant values in Eqs. (10) and (11) are as follows [34]

$C_{\varepsilon 1}=1.44$

$C_{\varepsilon 2}=1.92$

$C_{\mu}=0.09$

$\sigma_{\kappa}=1$

$\sigma_{\varepsilon}=1.3$

\section{Boundary conditions}

The problem is investigating a three-dimensional, steadystate, forced turbulent convection of alumina nanofluid with different volume fractions (1-4\%) inside a circular tube with length of $100 \mathrm{~mm}$ and diameter of $10 \mathrm{~mm}$ and also comparing the result with pure water. This tube is a part of monoblocks of a divertor acting as heat sink for removing high heat loads from the plasma which in direct contact with monoblock surface.

Impermeable boundary and no-slip wall conditions are implemented over the surfaces of walls. The top surface (tungsten) is subjected to high heat flux of $10 \mathrm{MW} / \mathrm{m}^{2}$. In fact, a constant heat flux is considered for the top wall in order to absorb the heat. The fluid (pure water with $\phi=0$ or nanofluid with $\phi=1-4 \%$ ) flowing inside the tube enters with a uniform temperature $\left(T_{\text {inlet }}\right)$ and also an axial uniform velocity profile $\left(V_{\text {inlet }}\right)$ of different values associated with a range of Reynolds numbers, here varied from 80,000 to 150,000 . The uniform velocity profile is a common way of considering the inlet flow condition in order to determine the Reynolds number according to its formula. The pressure outlet has been chosen for the tube outlet boundary condition, while the velocity gradients are fixed to zero value. This pressure has been set at 4.2 $\mathrm{MPa}$.

According to these conditions:

$V_{x}=0 . V_{y}=0 . V_{z}=V_{\text {inlet }}$

$T_{\text {inlet }}=393.15 \mathrm{~K}$.

$P_{\text {outlet }}=4.2 \mathrm{MPa}$

At the fluid wall interface, there is a constant heat flux as:

$q=-\left.k_{\mathrm{nf}} \frac{\partial T}{\partial y}\right|_{\text {wall }}$

The wall (here means the inner surface of the $\mathrm{CuCrZr}$ tube) is in the stationary state and no slip for motion and shear stress, respectively.

\section{Numerical method}

\section{Physical model}

The assumption mentioned in previous parts can be summarized as follows:

- The fluid is incompressible, non-Newtonian and turbulent in steady state.

- The fluid along the cooling channel remains in single phase.

- There is a thermal equilibrium between nanoparticles and base fluids and the relative velocity is equal to zero.

- Thermo-physical properties of fluids are constant.

\section{CFD simulation}

The governing equations (flow, turbulence and energy) with mentioned boundary conditions have been numerically solved using the finite volume method (FVM). It was done by using computational fluid dynamic (CFD) approach. CFD is a technique with the aim of studying fluid flow, heat transfer and other related phenomena based on computer simulations.

In this work, the CFD commercially available software FLUENT 6.3.26 has been used by the following reasonable steps: prepress stage in which the geometry for the CFD 
region has been constructed and the componential created in GAMBIT as it is shown in Fig. 3. The mesh file has been then exported to FLUENT. Then the physical model, boundary condition and other assumptions required for an accurate analysis (next paragraph) have been defined in FLUENT. It has been followed by solving stage. The favorable results like Nusselt number needed for investigation have been defined in the post-processing stage.

The main assumption considered in FLUENT is as follows. Pressure-based model has been used as solver, and semi-implicit method for pressure-linked equations (SIMPLE) model has been chosen for pressure-velocity coupling. $\kappa-\varepsilon$ model with standard wall functions and default setting has been used to simulate turbulence. To discretize equations, second-order upwind method has been selected. During the iteration process, the residuals for each variable have been monitored until the convergence criteria, restricted to be lower than $10^{-5}$, has been assured.

\section{Result and discussion}

As the result has been proposed based on average amounts of Nusselt number $\left(N u_{\text {av }}\right)$ and average heat transfer coefficient $\left(h_{\text {av }}\right)$, the equations to calculate them are defined as follows

$N u_{\mathrm{av}}=h_{\mathrm{av}} \frac{D}{k}$

$h_{\mathrm{av}}=\frac{1}{L} \int_{0}^{L} h(z) \mathrm{d} z$

where $L$ is length of the tube.

Hereinafter, the terms Nusselt and heat transfer coefficient refer to average amount, unless otherwise mentioned.

\section{Validation}

In order to investigate the validity of the numerical simulation done here, a comparison between the Nusselt numbers obtained in post-processing stage of calculation and two of the traditional equations which have been widely used in the literature for prediction of Nusselt numbers has been made. The first equation is recommended by Maiga et al. [35]

$N u=0.0858 \operatorname{Re}^{0.71} \operatorname{Pr}^{0.35}$

for

$6.6<\operatorname{Pr}<13.9 ; 10^{4}<\operatorname{Re}<5 \times 10^{5}$

where $\operatorname{Pr}$ is Prandtl number $\left(\frac{c_{p} \mu}{k}\right)$.

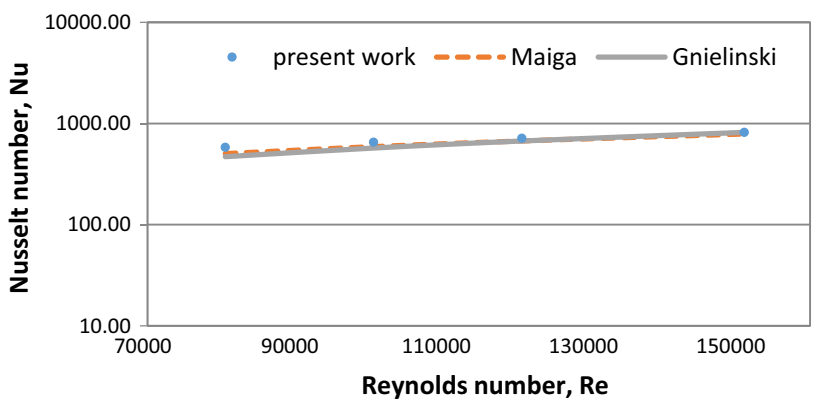

Fig. 5 Comparison of Nusselt number; results from Maiga and Gnielinski correlations with the present work (1\% alumina nanofluid)

Gnielinski [36] suggested another relation as follows:

$N u=0.012\left(R e^{0.87}-280\right) \operatorname{Pr}^{0.4}$

for

$1.5<\operatorname{Pr}<500 ; 3000<\operatorname{Re}<10^{6}$

Figure 5 displays the comparison of Nusselt numbers from theoretical correlations proposed by Maiga and Gnielinski with the numerical results computed here by FLUENT. These results are for the case of a $1 \%$ volume fraction $\mathrm{Al}_{2} \mathrm{O}_{3}$ with Prandtl number of 6.71 .

It is clear from this figure that numerical results obtained here are in good agreement with these two theoretical results, especially for larger Reynolds numbers, so that at the Reynolds number of $150 \times 10^{3}$, the deviation of the numerical results from the equation given by Gnielinski and Maiga is $0.07 \%$ and $3.5 \%$, respectively. At lower Re numbers, Maiga correlation has better prediction of the numerical results with average deviation of $11 \%$. These results agree well with the literature published by Lotfi [37] and Namburu [29].

\section{Temperature distribution}

After the validation done by comparison in the previous section and confirming that the componential model presented here is giving correct results with acceptable deviation, temperature distribution has been considered.

Temperature contours of $\mathrm{CuCrZr}$ cooling tube for base fluid and nanofluid with volume fraction of $1 \%$, both at the same Reynolds number of 120000, are shown in Fig. 6. Moreover, Fig. 7 also illustrates the temperature contour for the whole divertor. It can be seen that the inclusion of nanoparticle into the base fluid has a bifacial effect on temperature of cooling tube.

$\mathrm{CuCrZr}$ wall tube and tungsten maximum static temperature dependence on Reynolds number and nanoparticle concentration is illustrated in Figs. 8 and 9. These figures show that increasing both the Reynolds number and volume fraction of nanoparticles decreases the wall temperature. In a constant Reynolds (i.e., 120,800), adding nanoparticles to $1 \%$ and $4 \%$ 
Fig. 6 Temperature contours at $\mathrm{CuCrZr}$ cooling tube for base fluid and nanofluid
Base fluid $(\mathrm{Re}=120800)$

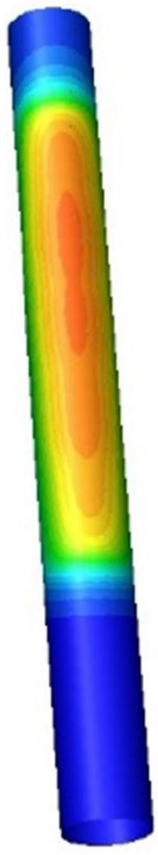

Base fluid $(\operatorname{Re}=120800)$

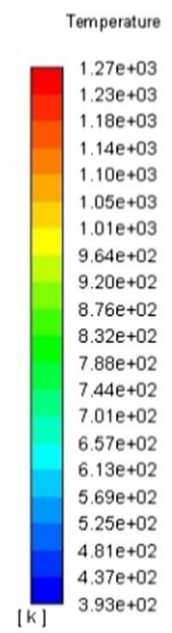

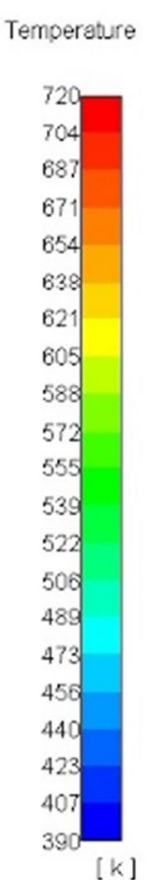

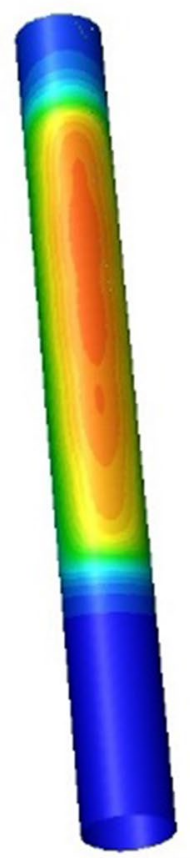

nanofluid $1 \%$ vol. $(\operatorname{Re}=120800)$

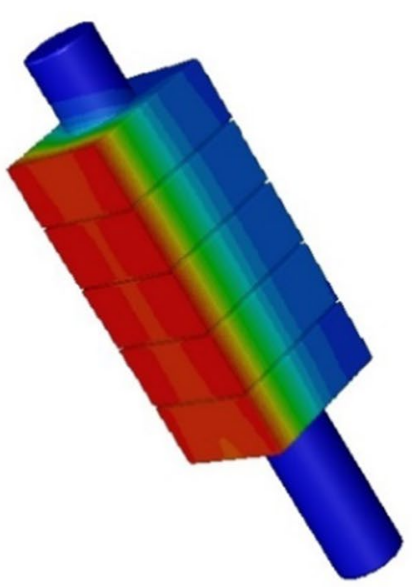

nanofluid $1 \%$ vol. $(\mathrm{Re}=120800)$

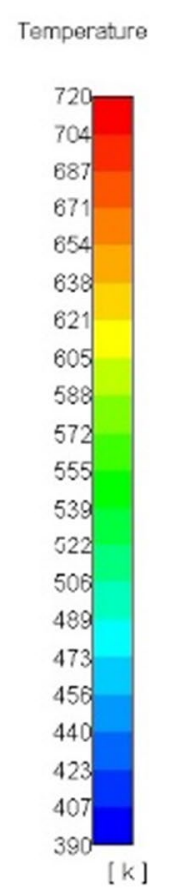

Fig. 7 Temperature contours for the whole divertor for base fluid and nanofluid

volume fraction will decrease the $\mathrm{CuCrZr}$ tube temperature $4 \mathrm{~K}$ and $16 \mathrm{~K}$, respectively, with respect to base fluid. This decrease is $4 \mathrm{~K}$ and $15 \mathrm{~K}$ for tungsten. Also, from the volume Reynolds number viewpoint, increasing the $R e$ numbers from 80,500 to 151,000 (at a constant volume fraction) leads to the decrease in the maximum temperature of the $\mathrm{CuCrZr}$ tube from 792 to 676 Kelvin (pure water), 787 to 668 (1\% nanofluid) and 776 to 666 (4\% nanofluid). These reductions are $102 \mathrm{~K}, 101 \mathrm{~K}$ and $97 \mathrm{~K}$, respectively, for that of tungsten surface.

\section{Temperature limitation on $\mathrm{W}$ and $\mathrm{CuCrZr}$}

One of the important issues in choosing appropriate material to be used in divertor part is the existence of some limitation especially for maximum temperature of these materials above which some failures might happen. According to high heat load test on $\mathrm{W}$, above $1573 \mathrm{~K}$ recrystallization occurs and affects $\mathrm{W}$ thermo-mechanical properties [38]. On the 


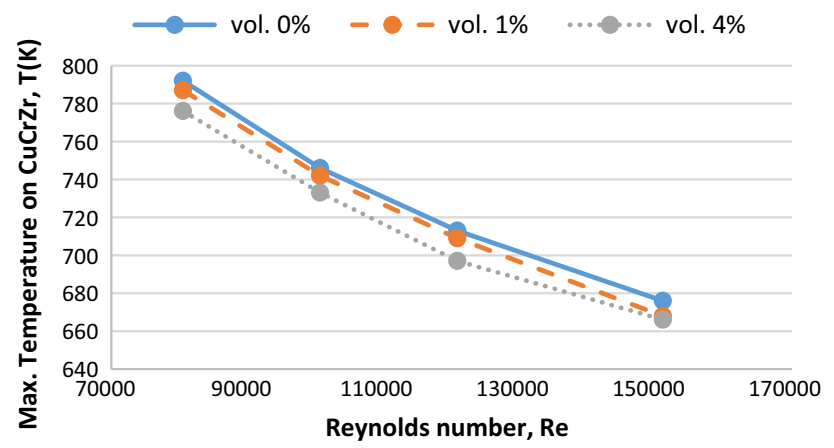

Fig. 8 Maximum temperature at $\mathrm{CuCrZr}$ cooling tube

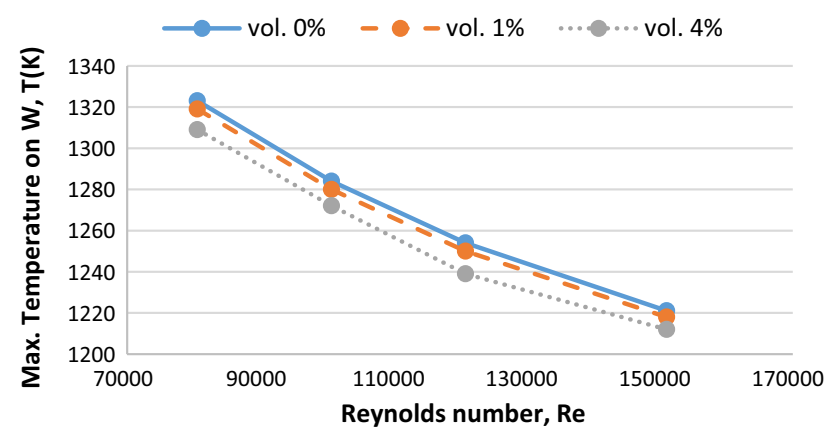

Fig. 9 Maximum temperature at tungsten

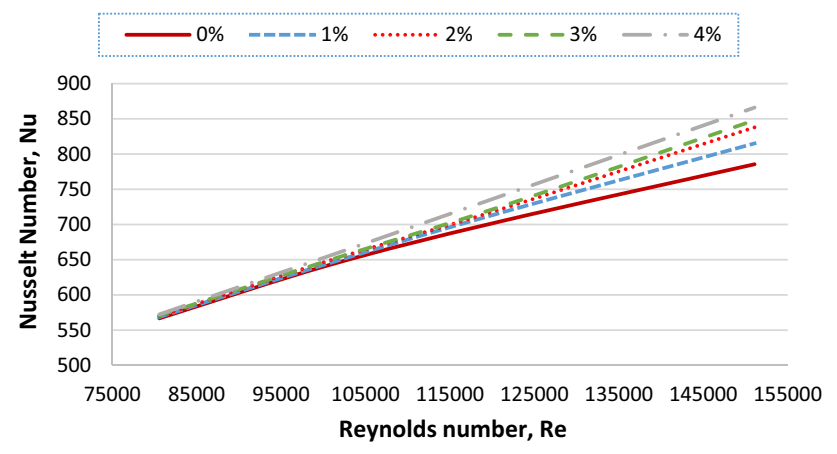

Fig. 10 Average Nusselt number for base fluid and nanofluids

other hand, the maximum temperature for $\mathrm{CuCrZr}$ must be lower than $823 \mathrm{~K}$, the upper temperature limit below which $\mathrm{CuCrZr}$ has its optimum thermo-mechanical behavior.

As Figs. 8 and 9 show, in all Reynolds number and volume fractions of nanoparticles, the maximum temperatures for these two materials are in agreement with these limitations. Among all cases considered in these two figures, the maximum temperatures for $\mathrm{W}$ and $\mathrm{CuCrZr}$ have been seen at the lowest Reynolds number and volume fraction: $1323^{\circ} \mathrm{C}$ and $792{ }^{\circ} \mathrm{C}$, respectively.

\section{Average Nusselt number}

Average Nusselt number for alumina nanofluids with volume fraction of $1-4 \%$ for considered Reynolds numbers is shown in Fig. 10. The results for pure water have also been included as solid line. It can be seen that by adding nanoparticles to pure water, even in the low volume fraction of $1 \%$, improvement in heat transfer has been achieved. Moreover, heat transfer increases at both particle volume concentration and Re numbers increasing, so that we have maximum Nusselt number at highest volume fraction and $R e$. The reason is that by increasing the volume fraction of nanoparticles, thermo-physical properties of fluid are improved, including higher thermal conductivity and Prandtl number, with respect to pure water. On the other hand, the difference between the temperatures of $\mathrm{CuCrZr}$ wall and fluid is decreased in comparison with pure water, leading to an increase in heat transfer coefficient as Nusselt number.

Experimental studies $[39,40]$ have shown that increments in heat transfer coefficients by inclusion of nanoparticles inside the base fluid are higher than what expected by numerical results, which means that improving the thermo-physical properties is not the only phenomenon attributing to heat transfer improvement.

\section{Conclusion}

Numerical solution has been obtained to investigate heat transfer characteristics of alumina/water nanofluid flowing throw the horizontal cooling tube of a monoblock which is part of the important divertor system of fusion reactors. Steady-state turbulent convective heat transfer of this nanofluid under the high heat load of $10 \mathrm{MW} / \mathrm{m}^{2}$ was presented by CFD approach using FLUENT. The validity of CFD results was investigated by comparison with traditional expressions given by Maiga and Gnielinski and resulted in good agreement.

Temperature profiles for $\mathrm{CuCrZr}$ and tungsten sections of monoblock for the both cases of $1 \% \mathrm{Al}_{2} \mathrm{O}_{3}$ nanofluid and pure water revealed that adding even low concentration of nanoparticles can noticeably reduce temperature of these parts due to improvement in heat removal capacity. Also, maximum temperature profiles at $\mathrm{W}$ and $\mathrm{CuCrZr}$ for $1 \%$ and $4 \%$ volume fraction and base fluid illustrated that nanofluid can noticeably reduce maximum temperatures. It was concluded that using nanofluid can help the material to operate in their allowed temperature limitation. Moreover, average heat transfer study of nanofluids with different volume fractions (1-4\%) showed enhancement in heat transfer with respect to pure water. The higher the 
concentration, the more the heat transfer improvement. Enhancement of heat transfer by increasing Reynolds numbers was also concluded from this study.

Acknowledgement This work was supported by the Nuclear Science and Technology Research Institute (NSTR) and vice president research of University of Guilan.

\section{Compliance with ethical standards}

Conflict of interest The authors declare that they have no conflict of interest.

Open Access This article is distributed under the terms of the Creative Commons Attribution 4.0 International License (http://creativeco mmons.org/licenses/by/4.0/), which permits unrestricted use, distribution, and reproduction in any medium, provided you give appropriate credit to the original author(s) and the source, provide a link to the Creative Commons license, and indicate if changes were made.

\section{References}

1. Göktepe, S., Atalık, K., Ertürk, H.: Comparison of single and two-phase models for nanofluid convection at the entrance of a uniformly heated tube. Int. J. Therm. Sci. 80, 83-92 (2014)

2. Sheikholeslami, M., Hatami, M., Domairry, G.: Numerical simulation of two phase unsteady nanofluid flow and heat transfer between parallel plates in presence of time dependent magnetic field. J. Taiwan Inst. Chem. Eng. 46, 43-50 (2015)

3. Li, L., et al.: Optimization of the water-cooled structure for the divertor plates in EAST based on an orthogonal theory. Plasma Sci. Technol. 17(5), 435 (2015)

4. Autissier, E., et al.: Design optimization of plasma facing component with functional gradient material $\mathrm{Cu} / \mathrm{W}$ interlayer. Fusion Eng. Des. 88(9-10), 1714-1717 (2013)

5. Li, M., Werner, E., You, J.-H.: Fracture mechanical analysis of tungsten armor failure of a water-cooled divertor target. Fusion Eng. Des. 89(11), 2716-2725 (2014)

6. Chen, P., et al.: Preliminary thermo-hydraulic and mechanical analysis for CFETR divertor. J. Fusion Energy 34(4), 901-904 (2015)

7. Li-Puma, A., et al.: Potential and limits of water cooled divertor concepts based on monoblock design as possible candidates for a DEMO reactor. Fusion Eng. Des. 88(9-10), 1836-1843 (2013)

8. Richou, M., Li-Puma, A., Visca, E.: Design of a water cooled monoblock divertor for DEMO using Eurofer as structural material. Fusion Eng. Des. 89(7-8), 975-980 (2014)

9. Zhu, D., Chen, J.: Thermal stress analysis on chemical vapor deposition tungsten coating as plasma facing material for EAST. J. Nucl. Mater. 455(1-3), 185-188 (2014)

10. Chong, F.L., Chen, J.L., Li, J.G.: Thermal analysis of tungsten coating on $\mathrm{CuCrZr}$ with different interlayers used as EAST divertor target materials. Mater. Des. 29(8), 1675-1678 (2008)

11. Barrett, T.R., et al.: Investigating the use of nanofluids to improve high heat flux cooling systems. Fusion Eng. Des. 88(9-10), 25942597 (2013)

12. Sergis, A., Hardalupas, Y.: Anomalous heat transfer modes of nanofluids: a review based on statistical analysis. Nanoscale Res. Lett. 6(1), 391 (2011)

13. Zarifi, E., Jahanfarnia, G., Veysi, F.: Neutronic simulation of water-based nanofluids as a coolant in VVER-1000 reactor. Prog. Nucl. Energy 65, 32-41 (2013)
14. Wu, J.M., Zhao, J.: A review of nanofluid heat transfer and critical heat flux enhancement-research gap to engineering application. Prog. Nucl. Energy 66, 13-24 (2013)

15. Utomo, A.T., et al.: Experimental and theoretical studies of thermal conductivity, viscosity and heat transfer coefficient of titania and alumina nanofluids. Int. J. Heat Mass Transf. 55(25-26), 7772-7781 (2012)

16. Lee, S., et al.: Measuring thermal conductivity of fluids containing oxide nanoparticles. J. Heat Transfer 121(2), 280-289 (1999)

17. Zarifi, E., Jahanfarnia, G., Veysi, F.: Thermal-hydraulic modeling of nanofluids as the coolant in VVER-1000 reactor core by the porous media approach. Ann. Nucl. Energy 51, 203-212 (2013)

18. Davarnejad, R., Jamshidzadeh, M.: CFD modeling of heat transfer performance of $\mathrm{MgO}$-water nanofluid under turbulent flow. Eng. Sci. Technol. Int. J. 18(4), 536-542 (2015)

19. Noie, S.H., et al.: Heat transfer enhancement using $\mathrm{Al}_{2} \mathrm{O}_{3}$ /water nanofluid in a two-phase closed thermosyphon. Int. J. Heat Fluid Flow 30(4), 700-705 (2009)

20. Drew, D.A., Passman, S.L.: Theory of Multicomponent Fluids. Springer, Berlin (1999)

21. Hamilton, R.L., Crosser, O.K.: Thermal conductivity of heterogeneous two-component systems. Ind. Eng. Chem. Fundam. 1(3), 187-191 (1962)

22. Hemmat Esfe, M., Saedodin, S., Mahmoodi, M.: Experimental studies on the convective heat transfer performance and thermophysical properties of $\mathrm{MgO}$-water nanofluid under turbulent flow. Exp. Therm. Fluid Sci. 52, 68-78 (2014)

23. Wen, D., Ding, Y.: Experimental investigation into convective heat transfer of nanofluids at the entrance region under laminar flow conditions. Int. J. Heat Mass Transf. 47(24), 5181-5188 (2004)

24. Jung, J.-Y., Oh, H.-S., Kwak, H.-Y.: Forced convective heat transfer of nanofluids in microchannels. Int. J. Heat Mass Transf. 52(1-2), 466-472 (2009)

25. Maxwell, J.C.: A Treatise on Electricity and Magnetism. Clarendon, Oxford (1881)

26. Brinkman, H.C.: The viscosity of concentrated suspensions and solutions. J. Chem. Phys. 20(4), 571 (1952)

27. Nazififard, M., et al.: Numerical simulation of water-based alumina nanofluid in subchannel geometry. Sci. Technol. Nucl. Install. 2012, 12 (2012)

28. Xuan, Y., Li, Q.: Investigation on convective heat transfer and flow features of nanofluids. J. Heat Transf. 125(1), 151-155 (2003)

29. Namburu, P.K., et al.: Numerical study of turbulent flow and heat transfer characteristics of nanofluids considering variable properties. Int. J. Therm. Sci. 48(2), 290-302 (2009)

30. Corcione, M., Cianfrini, M., Quintino, A.: Heat transfer of nanofluids in turbulent pipe flow. Int. J. Therm. Sci. 56, 58-69 (2012)

31. Wilcox, D.C.: Turbulence Modeling for CFD. DCW Industries Inc, California (1994)

32. Fluent, I.: FLUENT 6.3 User's Guide. Fluent, Inc, Lebanon (2006)

33. Roy, G., et al.: Heat transfer performance and hydrodynamic behavior of turbulent nanofluid radial flows. Int. J. Therm. Sci. 58, 120-129 (2012)

34. He, Y., et al.: Numerical investigation into the convective heat transfer of $\mathrm{TiO}_{2}$ nanofluids flowing through a straight tube under the laminar flow conditions. Appl. Therm. Eng. 29(10), 19651972 (2009)

35. El Bécaye Maïga, S., et al.: Heat transfer enhancement in turbulent tube flow using $\mathrm{Al}_{2} \mathrm{O}_{3}$ nanoparticle suspension. Int. J. Numer. Meth. Heat Fluid Flow 16(3), 275-292 (2006)

36. Rostamani, M., et al.: Numerical study of turbulent forced convection flow of nanofluids in a long horizontal duct considering variable properties. Int. Commun. Heat Mass Transf. 37(10), 1426-1431 (2010) 
37. Lotfi, R., Saboohi, Y., Rashidi, A.M.: Numerical study of forced convective heat transfer of Nanofluids: comparison of different approaches. Int. Commun. Heat Mass Transf. 37(1), 74-78 (2010)

38. Gavila, P., et al.: High heat flux testing of mock-ups for a full tungsten ITER divertor. Fusion Eng. Des. 86(9-11), 1652-1655 (2011)
39. Pak, B.C., Cho, Y.I.: Hydrodynamic and heat transfer study of dispersed fluids with submicron metallic oxide particles. Exp. Heat Transf. 11(2), 151-170 (1998)

40. Xuan, Y., Roetzel, W.: Conceptions for heat transfer correlation of nanofluids. Int. J. Heat Mass Transf. 43(19), 3701-3707 (2000) 